\title{
CROSS-COUNTRY DIFFERENCES IN PRODUCTIVITY: THE ROLE OF ALLOCATION AND SELECTION
}

\author{
Eric J. Bartelsman \\ John C. Haltiwanger \\ Stefano Scarpetta \\ Working Paper 15490 \\ http://www.nber.org/papers/w15490 \\ NATIONAL BUREAU OF ECONOMIC RESEARCH \\ 1050 Massachusetts Avenue \\ Cambridge, MA 02138 \\ November 2009
}

We are also indebted to comments received on earlier drafts and presentations from Susanto Basu, Mary Hallward-Driemeier, John Fernald, Chang-Tai Hsieh, Pete Klenow, Ariel Pakes, Amil Petrin, and John Sutton as well as to participants from the World Bank Conferences on the "Microeconomics of Growth" and on "Firm Dynamics" and the NBER Summer Institute. We thank the International Growth Centre, the World Bank, and the OECD for financial support. The views expressed in this paper are those of the authors and should not be held to represent those of the OECD, its Member countries, or the National Bureau of Economic Research.

NBER working papers are circulated for discussion and comment purposes. They have not been peerreviewed or been subject to the review by the NBER Board of Directors that accompanies official NBER publications.

(C) 2009 by Eric J. Bartelsman, John C. Haltiwanger, and Stefano Scarpetta. All rights reserved. Short sections of text, not to exceed two paragraphs, may be quoted without explicit permission provided that full credit, including $(\mathcal{O}$ notice, is given to the source. 
Cross-Country Differences in Productivity: The Role of Allocation and Selection

Eric J. Bartelsman, John C. Haltiwanger, and Stefano Scarpetta

NBER Working Paper No. 15490

November 2009

JEL No. E02,L11,L16,L2,L25,O4,O57

\begin{abstract}
This paper combines different strands of the productivity literature to investigate the effect of idiosyncratic (firm-level) policy distortions on aggregate outcomes. On the one hand, a growing body of empirical research has been relating cross-country differences in key economic outcomes, such as productivity or output per capita, to differences in policies and institutions that shape the business environment. On the other hand, a branch of empirical research has attempted to shed light on the determinants of productivity at the firm level and the evolution of the distribution of productivity across firms within each industry. In this paper, we exploit a rich source of data with harmonized statistics on firm level variation within industries for a number of countries. Our key empirical finding is that there is substantial variation in the within-industry covariance between size and productivity across countries, but this covariance varies significantly across countries and is affected by the presence of idiosyncratic distortions. We develop a model in which heterogeneous firms face adjustment frictions (overhead labor and quasi-fixed capital) and idiosyncratic distortions. We show that the model can be readily calibrated to match the observed cross-country patterns of the within-industry covariance between productivity and size and thus help to explain the observed differences in aggregate performance.
\end{abstract}

Eric J. Bartelsman

Dept. of Economics, 2E-66

Vrije Universiteit Amsterdam

De Boelelaan 1105

1081 HV Amsterdam

The Netherlands

ebartelsman@alum.mit.edu

John C. Haltiwanger

Department of Economics

University of Maryland

College Park, MD 20742

and NBER

haltiwan@econ.umd.edu
Stefano Scarpetta

OECD

Directorate for Employment, Labour and Social Affairs

2 , rue Andrè-Pascal

75775 Paris Cedex 16, France

stefano.scarpetta@oecd.org 


\section{Introduction}

A vast theoretical and empirical literature has been devoted to identify the sources of the large and persistent differences in productivity across countries. A parallel literature has emerged over the past decade to analyse the heterogeneity in firm-level productivity within industries observed in the firm-level datasets that have become available in a wide variety of countries (e.g. Bartelsman, Haltiwanger, and Scarpetta (2004)).

A recent line of enquiry has been devoted to establish connections between these two literatures. In particular, it has focused on assessing how cross country differences in economic outcomes, such as productivity, relate to differences in the within-industry productivity dispersion across firms. For example, recent papers explore the interplay between the heterogeneity in firm-level productivity, the business environment and economic performance at the aggregate level (see e.g. Restuccia and Rogerson (2008), Hsieh and Klenow, (2009) and Alfaro et. al. (2008)). In this emerging literature, an open question is which measures of firmlevel variation are most instructive for detecting misallocation distortions. Hsieh and Klenow (2009) argue, for example, that higher dispersion of productivity across firms within a given industry in China and India relative to the U.S. reflects greater misallocation of resources in China and India.

Our paper provides a significant contribution to this line of research along two broad lines. First, we argue that a more robust moment to assess the impact of misallocation distortions, both theoretically and empirically, is the within-industry covariance between size and productivity. Second, we extend recent theoretical models to allow for distortions to play a role 
not only in the allocation of resources amongst existing firms but also in the selection of firms in the market and the degree of firm churning. ${ }^{2}$

The motivation for our approach is that the empirical evidence from firm-level data sources has shown that the widespread heterogeneity in firm-level performance is accompanied by substantial heterogeneity in the size of firms even within narrowly-defined industries. Moreover, consistent with core models of the size distribution of firms (e.g., Lucas (1978) and Melitz (2003)), there is evidence in the firm-level data that the distributions of productivity and size exhibit a positive correlation - that is to say, more productive firms tend to be larger than less productive ones. Our cross-country data suggest that there is considerable variation in the strength of the link between productivity and size across countries, between industries, and over time. The working hypothesis of this paper is that policy-induced misallocation distortions may be the source of the observed variation in this covariance across countries.

This misallocation hypothesis is not new (see, e.g., the discussion of these ideas in the literature in the handbook paper by Banerjee and Duflo (2005)) but the development of firmlevel databases in a variety of countries now permits exploring this issue more directly. In this paper, we explore the misallocation hypothesis using a variety of moments drawn from a harmonized firm-level database for the U.S. and a number of European countries, including transition economies of Eastern Europe. Our focus is to assess the extent to which distortions can account for the observed differences across countries and over time in the within-industry productivity dispersion, as discussed by Hsieh and Klenow, and in our preferred measure of the covariance between productivity and size. Further, we emphasize that distortions not only affect the allocation of resources across firms, but also the selection of firms producing in each market. 
To quantify the within-industry covariance between size and productivity, we use an established empirical decomposition of the level of industry productivity as proposed by Olley and Pakes (hereafter OP, 1996). The OP decomposition splits an index of industry-level productivity, defined as the weighted average of firm-level (log-)productivity, into an unweighted firm-level average and a covariance term. The covariance term is a summary measure of the within-industry cross sectional covariance between size and productivity. In our analysis, we find that the OP covariance term for labor productivity averages about $50 \log$ points within U.S. manufacturing industries: in an accounting sense, this implies that the industry index of labor productivity in the average U.S. manufacturing industry is 50 percent higher than it would be if employment shares were randomly allocated within industries. However, the OP covariance term only reaches 20-30 log points in Western Europe and it was close to zero, if not negative, in Central and Eastern European countries at the beginning of their transition to a market economy. Quite remarkably, the covariance term increased substantially during the 1990s as the transition process progressed in these countries.

The use of the OP covariance term to explore the role of market distortions is, of course, not new. In their seminal contribution, Olley and Pakes found that the covariance term (using a decomposition of industry Total Factor Productivity, TFP) increased substantially in the U.S. telecommunications equipment industry following the deregulation of the sector in the early 1980s. They argued that this was because the deregulation permitted outputs and inputs to be reallocated more readily from less productive to more productive firms.

We focus our analysis on three moments of the firm-level distributions, the withinindustry standard deviation of labor productivity and of total factor productivity, and the withinindustry covariance between labor productivity and employment shares. The individual 
moments, as well as the relationship between them, prove instructive in assessing the role of misallocation and this class of models. We find (consistent with recent literature -- see Syverson (2004a)) that the within-industry dispersion of labor productivity is larger than the withinindustry dispersion of total factor productivity. ${ }^{3}$ Our database of harmonized moments shows that this finding is robust across the countries, industries and time periods studied.

This finding is difficult to reconcile with many of the standard models in the literature, insofar as they have specific features that do not allow for any dispersion in labor productivity. In particular, the production function is often assumed to be Cobb-Douglas or, more generally, has the property that the average product of labor is proportional to the marginal product of labor. Moreover, many models make assumptions so that profit-maximizing firms equate the marginal revenue product of labor to the market wage. These two assumptions together imply that there should be no dispersion in labor productivity within industries (in the absence of distortions) even if there is significant dispersion in physical TFP. Our model includes frictions - even in the absence of misallocation distortions -- such as overhead labor and quasi-fixed capital that yield dispersion in labor productivity and can account for the observed dispersion in labor productivity being larger than in TFP.

In accounting for these features, we are careful to distinguish between physical and revenue-based measures of productivity in the model and the data, as emphasized in the recent literature (Foster, Haltiwanger and Syverson (2008) and Hsieh and Klenow (2009)). In particular, the frictions in our model imply that even in the absence of distortions there will be substantial dispersion in revenue based measures of labor productivity and total factor productivity and that each of these alternative measures of productivity will be positively 3 Syverson (2004b) reports that, within narrowly defined industries, the difference in the U.S. between the 90th and the 10th percentiles of the firm-level productivity distributions is about 99 log points for total factor productivity (TFP) and about $140 \log$ points for labor productivity. 
correlated with each other. A further implication is that the core prediction from models of firm heterogeneity of a positive covariance between physical output and physical productivity extends to predictions of a positive covariance between measures of size and productivity using the revenue based measures of productivity.

Furthermore, our simple model allows comparing and contrasting the effect of distortions on different moments in the data. For example, Hsieh and Klenow (2009) present evidence that dispersion in revenue-based measures of TFP is higher in China and India than in the United States. They use the quantitative variation in such measures of dispersion to back out the implied distortions that can account for these patterns. In our setting, we have similar measures of dispersion in revenue based TFP for eight countries, but we also have the measures of the dispersion of revenue-based labor productivity as well as the covariance between firm size and revenue labor productivity for the same countries.

To preview our main results, we find that the model can be readily calibrated to match the cross-country, within-industry patterns of the covariance of productivity and size, while it is more difficult to match the cross-country within-industry productivity dispersion patterns in the data. As will become clear, the reason is that the cross-country productivity dispersion patterns in the data and the model are less systematic than the cross-country covariance patterns.

The paper proceeds as follows. Section 2 describes the harmonized firm-level database used in our empirical analysis and presents some basic facts about the within-country productivity dispersion (TFP and labor productivity) as well as the empirical OP decompositions of productivity. In Section 3, we develop our model of allocative efficiency with idiosyncratic distortions in the selection and allocation process. Section 4 calibrates the model numerically to explore its implications in light of the empirical patterns discussed in Section 2. Section 5 
reports the results from the numerical simulations of the impact of misallocation distortions on

the key moments and explore the extent to which we can match the cross-country patterns of key moments observed in the data. Section 6 reviews our results relative to those presented in recent literature, while Section 7 presents a sensitivity analysis in which allow one key feature of our model - the degree of overhead labor - to vary. Section 8 presents our concluding remarks.

\section{The harmonized firm-level database and indicators of dispersion and covariance}

For the empirical analysis in this paper, we use firm-level moments drawn from a harmonized firm-level database that covers five industrial economies and three transition economies of Eastern Europe. ${ }^{4}$ The database was constructed using firm-level data from business registers, social security and corporate tax rolls, and enterprise surveys. ${ }^{5}$ In the construction of the database, particular attention was devoted to harmonizing key concepts (e.g. the definition of the unit of measurement) as well as to using common methods to compute the indicators. A detailed technical description of the dataset and the measures of outputs, inputs, deflators and productivity measures can be found in Bartelsman, Haltiwanger, and Scarpetta (2009) but we provide a brief overview here.

The overall database covers as many as 24 countries (a downloadable version of the data can be found at http://econweb.umd.edu/ haltiwan/BHS_jobflows_productivity/). However, given the focus on withinindustry dispersion of labor and multi-factor productivity and on the OP covariance term we restrict our attention in this paper to the U.S. and European (including transition) economies for which we have the required industry-level data. One of the countries that we include in the analysis (Germany) does not have the required within-industry multi-factor productivity measures but we include it nonetheless given its relevance in the cross-country comparison.

The firm-level database was assembled as part of long-term research projects sponsored by the OECD, the World Bank and Eurostat. The methodology for collecting the country/industry/time panel dataset built up from underlying micro-level datasets has been referred to as 'distributed micro-data analysis' (Bartelsman et al. 2004). A detailed technical description of the dataset may be found in Bartelsman, Haltiwanger and Scarpetta (2009). Harmonized code for creating the indicators were distributed to experts with access to the relevant data in each country (typically a researcher with access to the firm-level data or a staff member of the national statistical agency). 
The firm-level data of the eight countries included in our analysis cover the manufacturing sector and include variables permitting consistent measurement of output, employment, materials and capital inputs. The measure of gross output is based on sales data at the firm-level deflated with an industry level deflator (2- or 3-digit industries). The measure of labor input is based on the number of employees, while the measure of capital is based on book values, with further adjustments described in detail in Bartelsman, Haltiwanger and Scarpetta (2009). The measure of materials is based on nominal materials expenditures deflated with an industry-level materials deflator. Total factor productivity calculations use expenditure shares for labor, capital and materials. ${ }^{6}$ Since all gross output and materials are deflated with industrylevel deflators, the measures of real labor productivity (LPR) and real multi-factor productivity (TFPR) are revenue-based measures so they do not control for within-industry variation in firmlevel prices. ${ }^{7}$

There are a number of conceptual and measurement (e.g., index number) problems in comparing productivity across countries and, within each of them, across industries. We avoid some of these problems by focusing on within-industry measures of dispersion and covariance. Moreover, in order to facilitate cross-country comparisons and, in particular, to remove the possible influence of differences in the industry composition of the manufacturing sector in the cross-country comparisons, we construct country-level indexes by taking the weighted average of the within-industry measures using a common set of industry weights. In particular, for all of

6 The measure of TFPR we use here is denoted as MFP in the Bartelsman, Haltiwanger and Scarpetta (2009) paper and dataset.

In our theoretical model, frictions will yield a high, positive correlation between LPR, TFPR, and TFPQ across firms in the same industry. The empirical evidence for the U.S. supports such high correlations for example, Foster, Haltiwanger and Syverson (2008) find a correlation of about 0.7 for TFPR and TFPQ in the U.S. Foster, Haltiwanger and Krizan (2001) find a correlation of about 0.4 between TFPR and LPR in the U.S. 
the data analysis in this paper, we use time-invariant U.S. industry gross output shares or labor shares as weights to aggregate over industries.

Three basic measures from these harmonized data are used in this paper: the withinindustry standard deviation of log revenue labor productivity STD(LPR); the within-industry standard deviation of log revenue total factor productivity STD(TFPR); and a measure of withinindustry covariance between size and productivity (OP). To compute the covariance measure we exploit the cross sectional decomposition of the following industry-level index of productivity developed by Olley and Pakes (1996). They note that an index of productivity for an industry, defined as the weighted average of firm-level productivity, can be decomposed as follows:

$\Omega_{t}=\sum_{i} \theta_{i t} \omega_{i t}=\bar{\omega}_{t}+\sum_{i}\left(\theta_{i t}-\bar{\theta}_{t}\right)\left(\omega_{i t}-\bar{\omega}_{t}\right)$

where $\Omega_{t}$ is the industry index, $\omega_{i t}$ is firm-level productivity, $\theta_{i t}$ is the share of activity for the firm, and a 'bar' over a variable represents the unweighted industry average of the firm-level measure. The industry index is comprised of two terms: the un-weighted average of firm-level productivity and a covariance term that reflects the extent to which firms with higher than average productivity have a higher than average market share.

It is the second term in this decomposition - the within-industry covariance term -- that we use in our analysis. By construction, the covariance term is not affected by country or industry-specific effects; as such it is exempted from possible measurement error that impacts first moments at the country or country-industry level. For the empirical analysis, we use $\log$ labor productivity at the firm level as our measure of $\omega_{i t}$ and the firm's labor share in the 
industry as our measure of $\theta_{\mathrm{it}}$. We focus on the covariance measure using labor productivity since it is more readily available at the industry level for our sample of countries. ${ }^{8}$

Table 1 shows the three moments of interest for the sample of eight countries used in this analysis. Several observations emerge from the table. First, the within-industry dispersion of both revenue labor productivity and revenue total factor productivity is large in every country. Second, within countries, the within-industry dispersion of revenue labor productivity always exceeds the within-industry dispersion of revenue total factor productivity. ${ }^{9}$ Thus, the finding by Syverson (2004b) is pervasive across countries, industries, and time. Third, the covariance term is positive for almost all countries but exhibits systematic and notable cross-country patterns: in particular, the covariance term is the highest in the U.S. manufacturing, it is much lower on average in the Western European countries and even lower in the transition economies of Eastern Europe. $^{10}$

It is also instructive to explore the within-country variation over time in these moments. These moments are available for a number of years spanning the period 1992-2001 for all countries, except France where data are available through 1995. We construct simple long differences for each moment by taking the difference between the average for the period 1996-2001 and the average for the period 1991-1995. Table 2 reports the within country changes of the moments computed in this fashion.

As will become clear, in the calibration analysis that follows we compute the moments in the model in the same fashion that we compute them in the data. For example we compute revenue labor productivity and compute the OP covariance term using revenue labor productivity and employment weights.

Of the nearly 1000 industry and year observations for the set of countries under study, the dispersion in revenue labor productivity exceeds the dispersion in revenue total factor productivity in all but 15 cases.

A slight exception to this pattern is that Hungary and the U.K. have about the same covariance term. While productivity performance were rather weak in the U.K. may be associated with the rather weak performance of aggregate productivity performance in the early 1990s (see e.g. Scarpetta (2003)). However, a new round of data collection for EU countries for the period 1998-2005 shows that the OP covariance term in the U.K. increased from 0.23 to 0.35 . 
A number of observations emerge. First, the covariance term increases substantially in the transition economies but increases only slightly in the U.S. and the Western European economies. This is consistent with the view that in Central and Eastern Europe the transition to a market-based system has, over time, allowed for a better allocation of resources; the U.S. had more stable market structures and economic institutions over this period and thus less marked changes in the covariance term. Second, the dispersion measures are relatively stable over time for the U.S. and Western European economies, but also in the transition economies.

Overall, the covariance term exhibits systematic cross-country variation in terms of both levels and changes. The within-industry dispersion measures are all large and relatively stable over time. In addition, there is a systematic pattern that the dispersion of labor productivity exceeds the dispersion of total factor productivity in all countries. These are the key features of the firm-level data that we confront with the model analysis below.

\section{A Model of Idiosyncratic Distortions, Selection and Allocation}

To guide our analysis of distortions and allocative efficiency we develop a model that shares some common features with Restuccia and Rogerson (2008) and Hsieh and Klenow (2009). In common with both models, we have production units with heterogeneous productivity that face idiosyncratic distortions. Further, the curvature in the profit function, necessary for an equilibrium of firms with heterogeneous productivity, comes from decreasing returns to scale and a downward sloping demand curve associated with a differentiated product environment. However, the model differs from the recent literature in a number of key dimensions. In particular, the model is developed to capture an important fact observed in the data in all countries: the dispersion in revenue labor productivity within industries exceeds the dispersion in revenue total factor productivity, even in economies with little or no distortions such as the U.S. 
To match this feature of the data, we include quasi-fixed capital in the presence of transitory productivity shocks and overhead labor.

Starting with the behaviour of firms, we assume that firms produce according to a production function given by: ${ }^{11}$

$$
Y_{i t}=A_{i} \varepsilon_{i t}\left(n_{i t}-f\right)^{\gamma-\alpha} k_{i t}^{\alpha}, \gamma<1
$$

where $Y_{i t}$ is output for firm $i$ in period $t, A_{i}$ is the firm-specific, time-invariant productivity component for firm $i, k_{i t}$ is the amount of capital input of firm $i$ at time $t, n_{i t}$ is employment, $f$ is overhead labor, and $\varepsilon_{i t}$ is an iid shock drawn from a time invariant distribution and observed each period after $k$ is chosen and the decision to produce has been made. We also allow for decreasing returns to scale, possibly related to some unobserved fixed factor - such as managerial ability, as in Lucas (1978). The decreasing returns hypothesis is one of the factors that insure that the most productive firm/manager does not take over the market. The overhead labor implies that the distribution of labor productivity is not degenerate even in an economy without distortions (i.e., while the marginal revenue product of labor will be set equal to the wage rate, the average product of labor will vary with scale, given overhead labor). Moreover, since capital is quasi-

We use a value-added production function in the theoretical model and in the calibration. This implies that both in the model and in the calibration, measures of real labor productivity are real value added per worker. Because information on expenditures on intermediate inputs is less comprehensive in the firmlevel data for some transition economies, we try to match the cross country moments of Table 1 that are computed using real gross output per worker instead of value added. While there is a potential for some mismatch, we think that it does not matter much in practice. The moments from Table 1 are withinindustry dispersion and covariance measures and the results in the literature show that real gross output per firm and real value added per firm are very highly correlated within the same industry (Foster, Haltiwanger and Krizan (2001)). In a related fashion, the within industry standard deviation of real gross output per worker shown in Table 1 for the U.S. (0.58) is almost identical to the standard deviation of real value added per worker that we calculated from the underlying data in an identical manner (0.60), and this is quite similar to dispersion in value added per worker for the U.S. calculated by Syverson (2004a). Further, for about 3600 of the 5200 country/industry/time observations in the distributed micro analysis database of moments (predominately industrialized countries), we can compute productivity dispersion for both gross output and value added per worker. The correlation between the two measures for this subsample is 0.82 . For the covariance measures, the correlation between the value-added and gross outputbased OP measures is .98 for industrialized countries, but drops to .58 in the transition countries. 
fixed, only labor will absorb the transitory shocks which, in turns, yields heterogeneity in the marginal revenue product of capital.

Firms face a downward demand schedule that arises from a differentiated products environment. The final good is assumed to be a CES aggregator of intermediate goods produced by the individual firms. The final goods sector is assumed to be perfectly competitive with the only inputs coming from intermediate goods. In particular:

$$
Y_{t}=N_{t}^{(\rho-1) / \rho}\left(\sum_{i} Y_{i t}^{\rho}\right)^{1 / \rho}
$$

where $\rho<1$. This implementation of the CES aggregator includes an adjustment factor to make the degree of substitution scale-free, as in Alessandria and Choi (2007) where $\mathrm{N}$ is the number of intermediate firms in operation. ${ }^{12}$ This implies that the inverse demand for good $i$ is given by:

$$
P_{i t}=P_{t}\left(\bar{Y}_{t} / Y_{i t}\right)^{1-\rho}
$$

where $P_{t}$ is the aggregate price for the final good and $\bar{Y}_{t}$ is average output measured as final output divided by $N$.

Firms producing the intermediate goods maximize profits, within an environment with distortions to nominal output, in each period given by:

$$
\pi_{i t}=\left(1-\tau_{i}-\kappa_{i t}\right) P_{t} \bar{Y}_{t}^{1-\rho}\left[A_{i} \varepsilon_{i t}\left(n_{i t}-f\right)^{\gamma} k_{i t}^{\alpha}\right]^{\rho}-w_{t} n_{i t}-R k_{i t}
$$

where $w_{t}$ is the wage paid to homogenous workers, and $R_{t}=r_{t}+\delta_{t}$, is the user cost of capital which equals the real interest rate plus the rate of depreciation. ${ }^{13}$ The firm-specific and time

As first noted by Benassy (1996) and discussed by Alessandria and Choi (2007), including this adjustment factor permits distinguishing between the love of variety effect and the impact of market power.

13 In an earlier version of this paper, we also considered an explicit "capital" disturbance that distorted the relative price of capital and labor. This distortion could also yield misallocation although we found that, in practice, it primarily impacts the mix of capital and labor. For purposes of brevity, we have excluded 
invariant disturbance to revenue, $\tau_{i}$, and the firm-specific time varying disturbance, $\kappa_{i t}$, can be interpreted broadly to include any distortion that impacts the scale of a business. The underlying motivation is that distortions to market structure and institutions have an idiosyncratic component, which may arise de jure as some regulations may only apply to firms above a certain size, or alternatively de facto as a result of favoritism or arbitrary and capricious behaviour of the public administration or other entities associated with problems of graft, corruption and rent seeking. The inclusion of idiosyncratic components of distortion is consistent with evidence that certain regulations apply differently to firms of different size, ${ }^{14}$ or with evidence from enterprise surveys (e.g. the World Bank Investment Climate Survey, ICA) that points to the fact that firms within a country face market and policy-driven obstacles, for starting up or conducting business, that exhibit a substantial idiosyncratic component. ${ }^{15}$

To make the model and analysis tractable, we assume a simple ex ante and ex post timing of information and decisions at any given period. Ex ante, before a new firm enters, we assume that firms do not know their production and distortion draws but they know the distribution of these idiosyncratic variables. There is a fixed cost of entry, $c_{e}$, that new firms must pay to enter and to learn their draws from the joint ex ante distribution of productivity and distortions, $G(A, \tau)$. Once a firm learns their draws of $A$ and $\tau$ their values remain constant over time. Each period the firm is subject to a further transitory idiosyncratic productivity shock from an ex-ante

this from the analysis but note that it is of interest to consider other sources of distortion beyond those that affect the scale as considered in this paper.

14 For example, regulations affecting the hiring and firing of workers only apply to firms above a certain threshold in a number of countries (see e.g. Venn, 2009).

15 In many developing and emerging economies, labor and other regulations are de facto enforced to a different degree across firms of different size, sectoral affiliation etc. (see e.g. Pierre and Scarpetta, 2006; World Bank, 2004; Aterido et al., 2007). 
known distribution, and an idiosyncratic transitory distortion shock that it learns after deciding whether to produce and choosing $k$ each period.

Firms discount the future at rate $\beta=1 / 1+r$ and face an exogenous probability of exiting in each period given by $\lambda$. Given free entry and the assumptions about the arrival of information, new firms enter up to the point where the expected discounted value of profits is just equal to the entry fee. Moreover, given that the draws are time invariant in the steady state, the present discounted value for an incumbent firm $i$ ex post is given simply by:

$$
W\left(A_{i}, \tau_{i}\right)=E\left[\pi\left(A_{i}, \tau_{i}, \kappa_{i t}, \varepsilon_{i t}\right)\right] /(1-\chi)
$$

where

$$
\chi=(1-\lambda) /(1+r)
$$

In turn, the free entry condition is given by:

$$
W^{e}=\int_{A, \theta . \tau} \max \left(0, W(A, \tau) d G(A, \tau)-c_{e}\right.
$$

where $c_{e}$ is the sunk entry cost.

New firms with a low productivity and/or a high scale distortion draw will exit immediately upon learning their draws, if they cannot cover their operating costs. In what follows, we find that the subset of firms that survive upon learning their productivity and distortion draws is an important factor for assessing the effects of distortions. The surviving subset, $M(A, \tau)$, is comprised of the firms that enter based on their knowledge of the distribution $G(A, \tau)$, but that did not exit owing to a non-positive present discounted value of operating profits, $W\left(A_{i}, \tau_{i}\right)$. Distortions thus influence the pace of churning of firms and, in this model, this is captured by the pace of entry (the number of firms deciding to pay the entry fee) and exit 
(the number of firms that exit upon learning their draws). Even more importantly, the distortions and their potential correlation with idiosyncratic productivity, affect which firms survive.

Conditional on survival, the distribution $M(A, \tau)$, and the equilibrium input prices will determine optimal firm-level capital input. In addition, given the optimal amount of capital, the labor choice will depend upon the realization of the transitory shocks. It is useful to start backwards within a period considering optimal employment for a given capital stock, which must satisfy:

$$
\gamma \rho\left(1-\tau_{i}-\kappa_{i t}\right)\left(P_{t} \bar{Y}_{t}^{1-\rho}\left[A_{i} \varepsilon_{i t} k_{i t}^{\alpha}\right]^{\rho}\left(n_{i t}-f\right)^{\gamma \rho-1}=w_{t}\right.
$$

In turn the optimal capital stock must satisfy:

(6) $k_{i t}=\left[\alpha A_{i}^{\rho} P_{t} E\left(\left(\bar{Y}_{t}^{1-\rho}\left(1-\tau_{i}-\kappa_{i t}\right)\left(\varepsilon_{i t}\left(n_{i t}-f\right)^{\gamma}\right)^{\rho}\right)\right) / R\right]^{1 /(1-\alpha \rho)}$

Output and profits for the operating firm are given by (1) and (2). Even though the firm is subject to a transitory productivity and distortion shock each period, the expected profits of the firm are the same every period and the optimal capital stock is the same every period. The firm adjusts to the ex post transitory productivity and disturbance draws, $\varepsilon_{i t}, \kappa_{i t}$, by adjusting employment. The firm is of course deciding whether to produce and choosing its capital, conditional on the distribution of these transitory disturbances. Even in the absence of distortions, there will be dispersion in revenue labor productivity given the overhead labor interacting with the heterogeneity in TFP and the heterogeneity in capital input.

To close the model we must describe labor supply and the behaviour of households and workers. A fixed number of households are assumed to supply labor inelastically so that aggregate labor supply is equal to $N^{s}$. Aggregate labor demand is given by the sum of labor 
demands for operating firms from (5). In equilibrium the number of firms and wages must satisfy both the free entry condition and the equality of labor demand and aggregate labor supply.

$W^{e}=0, N_{t}^{d}=N_{t}^{s}$

An aggregate resource constraint ensures that aggregate consumption plus resources spent on entry and depreciation will equal aggregate output in the stochastic steady state: ${ }^{16}$

$C_{t}+E_{t} c_{e}+\delta K_{t}=Y_{t}$

where $\mathrm{K}_{t}$ is the aggregate of capital of ex-post operating firms, and $\mathrm{E}_{\mathrm{t}}$ is the number of entrants.

The interest rate is pinned down by the production technology and utility maximization by the households. We assume a representative household that supplies labor inelastically and chooses consumption to maximize:

$\sum_{t=0}^{\infty} \beta^{t} U\left(C_{t}\right)$

Subject to the budget constraint:

$\sum_{t=0}^{\infty} p_{t}\left(C_{t}+K_{t+1}-(1-\delta) K_{t}\right)=\sum_{t=0}^{\infty} p_{t}\left(w_{t} N_{t}+R_{t} K_{t}+\pi_{t}\right)$

where $p_{t}$ is the time zero price of period $t$ consumption, $w_{t}$ and $R_{t}$ are the period $t$ rental prices of labor and capital measured relative to period t output, and $\pi_{t}$ is the total profit from the operations of all plants. A standard result emerges from the first order conditions of this problem given by:

16 In steady state gross investment is equal to replacement investment and net investment is zero. 
$r_{t}=R_{t}-\delta=(1 / \beta)-1$

So the real interest rate and rental cost of capital is pinned down by the discount factor for utility and the capital depreciation rate.

\section{Calibration of Benchmark “U.S.” Model}

We first develop a benchmark calibration intended to match U.S. moments. To accomplish this, a number of parameters are set based upon empirical evidence in the literature. We then choose the remaining benchmark parameters to match the U.S. moments from Table 1. For the purpose of this "benchmark" calibration, we make the assumption that the U.S. is a nondistorted economy and choose the parameters to match U.S. moments under the assumption that the distortions in the model are zero. ${ }^{17}$ In the analysis in the next sections, we assume that all countries face the same technology, the same distribution of technology shocks, the same curvature parameters of the profit function and then seek to account for the variation in Tables 1 and 2 across countries using variation in the distortion parameters alone.

In exploring the model simulations it is useful to note that there are a number of possible measures of firm-level productivity that are interesting to examine. The measure of physical TFP (what Foster et. al. (2008) and Hsieh and Klenow (2009) call TFPQ)) is given in the model by the product $A_{i} \varepsilon_{i t}$ with the permanent component of physical productivity given by $A_{i}$. The measure of revenue TFP (what Foster et. al. (2008) and Hsieh and Klenow (2009) call TFPR) and the associated measure of revenue labor productivity (what we refer to as LPR) are also of

17 The recent literature has focused on different moments to generate a U.S. benchmark. We provide some discussion of these alternatives in Section 6. 
interest. In what follows, we examine all of these different measures of firm-level productivity within the context of the model simulation. It is important to note that in our numerical analysis, the moments and decompositions we report are based on $\log (\mathrm{TFPQ}), \log (\mathrm{TFPR})$ and $\log (\mathrm{LPR}) .{ }^{18}$

We also note that in our numerical analysis of the theoretical model we consider an OP decomposition of revenue labor productivity that corresponds to what we measure in the data. That is, one of the OP decompositions we consider is based on the employment-share weighted average of firm-level log revenue labor productivity. Using the simulated moment that matches what we measure in the data permits us to benchmark to U.S. patterns and in turn seek to account for differences across countries on this moment. However, theoretically it is equally of interest to consider alternative moments capturing the covariance between size and productivity. In the simulations, we consider the OP covariance using TPPQ and physical output as well as the OP covariance using TFPR and revenue.

For our calibration of the non-distorted economy, we select the key parameters drawing from empirical evidence. In particular, ${ }^{19}$

- $\gamma=0.95$, (returns to scale - much of the evidence points towards close to constant returns to scale - see the discussion in Baily, Hulten and Campbell (1992), Syverson (2004a), Foster, Haltiwanger and Syverson (2008))

- $\alpha=0.3$, (capital output elasticity) so the implied labor elasticity $\gamma$ is 0.65 (these are close to standard choices for these parameters)

- $\lambda=0.10$, this is consistent with evidence of exit rates in the United States (see the Business Dynamic Statistics from the U.S. Census Bureau ${ }^{20}$ ) and other OECD countries In the discussion that follows in the text, when we refer to TFPQ, TFPR and LPR we typically omit the reference to logs for expositional convenience but in all cases log based measures are used.

19 We have conducted robustness analysis on each of these parameters and the findings in the paper are robust to reasonable variations in them. 
for businesses more than five years old (Bartelsman, Haltiwanger, and Scarpetta (2004) and $\mathrm{r}=.02$, and $\delta=.10$, consistent with long run real interest rates in OECD countries and typical depreciation rates from national accounts.

- $\rho=.8$, this is in the Broda and Weinstein (2006) range and implies a markup of 25 percent.

The remaining parameters include the overhead labor parameter $f$, the entry cost $c_{e}$ and the variances of the permanent and transitory productivity shocks. To pin these parameters down for the benchmark model, we use the information in Table 1 for the U.S. along with auxiliary information from the harmonized database on survival rates. Our model is not well suited to explore the dynamics of survival since there is not a rich, dynamic resolution of uncertainty or learning by doing that influences the selection dynamics of entering cohorts of businesses. However, our model has a simple form of endogenous selection of young businesses as entrants pay the entry fee, learn their productivity and distortion draws and decide whether or not to produce. To approximate this process, we use information on the exit rates of young businesses in the U.S. In our harmonized data, about 55 percent of businesses survive after five years in the U.S. This is about the same as found from other U.S. sources, such as the Business Dynamic Statistics from the U.S. Census Bureau. We match this moment in our calibration so that in the benchmark non-distorted economy 55 percent of the businesses that pay the sunk entry cost survive. We then seek to match the U.S. moments in Table 1. Not surprisingly, the survival, dispersion and covariance moments are all closely connected. For example, setting a high overhead labor parameter yields lower survival rates as fewer firms can cover their fixed

20 See http://www/ces.census.gov/index.php/bds/bds_home 
operating costs and, as we shall see, this selection effect impacts the dispersion and covariance moments.

In practice, we have found that we can match exactly the survival rate and one of the moments in Table 1 for the U.S. and approximately the other remaining moments in Table 1. The reason, as discussed in more detail below, is that the moments are nonlinear functions of key parameters. For our analysis, we have chosen to match exactly the OP covariance term so that in our benchmark calibration we have a survival rate of 55 percent and an OP covariance term of 0.51 (the value in Table 1 for the U.S.). For the standard deviation of revenue total factor productivity (TFPR) the benchmark calibration has 0.43 compared to 0.38 for the U.S. in Table 1. For the standard deviation of revenue labor productivity the benchmark calibration has 0.68 compared to 0.58 for the U.S. in Table 1. While we do not obtain exact matches to all of the relevant U.S. data moments, they are reasonably close and the calibrated benchmark model has the property that the standard deviation of revenue labor productivity exceeds the standard deviation of revenue total factor productivity as observed in the data. ${ }^{21}$

Some other properties of the benchmark model are worth noting since they are relevant for the analysis of distortions. In the calibrated model, we also compute the OP covariance term for revenue total factor productivity (in this case using revenue weights) and obtain an OP covariance term for TFPR of 0.41 . Likewise, we compute the OP covariance term using physical productivity in the model and obtain an OP covariance term of TFPQ of 0.96 (using physical output weights). Thus, the calibrated model has the property that more productive businesses are larger on a number of different dimensions. This is not surprising, since the source of

We have also considered benchmark calibrations where we benchmark to the U.S. standard deviation of TFPR instead of to the OP covariance. The impact of distortions is quite similar both qualitatively and quantitatively to what we present here. We focus on the benchmark calibrated to the OP covariance term in the U.S. since we can match exactly the OP covariance term patterns in Table 1 by permitting only the distribution of distortions to vary. 
heterogeneity in the benchmark model is idiosyncratic productivity variation and more productive businesses employ more workers, use more capital and produce more output. However, it is important to emphasize that it is the frictions that yield the dispersion in TFPR and LPR that would otherwise not be present even with dispersion in TFPQ. An accompanying implication is that the frictions implies that there is a high positive correlation between TFPQ, TFPR, and LPR in the benchmark calibration (all pairwise correlations are about 0.98 ).

Two other properties of the benchmark model are worth noting. First, in matching the moments, we obtain a share of overall labor that is accounted for by overhead labor of 0.17 . To put this in perspective, we note that in the U.S. manufacturing, non-production workers account for roughly 0.30 of total employment. Classifying all non-production workers as overhead labor is probably too strong an assumption, but our 0.17 is well within this upper bound estimate and seems not unreasonably high.

Another instructive statistic from the calibrated model is the share of overall output accounted for by entry costs. Recall that output is used for consumption, capital accumulation (replacing depreciated capital in equilibrium) and entry costs. In the non-distorted economy, we find that about 7 percent of output goes to entry costs. This reflects the costs incurred via the ongoing churning process with some businesses exiting on an ongoing pace and other businesses paying sunk entry costs to learn their draws and deciding to exit conditional on bad news. As will become clear, this statistic is sensitive to the distortions and will be one of the factors that influence the relationship between distortions and consumption.

Before proceeding to the effects of the idiosyncratic distortions, it is worth highlighting the role that overhead labor plays in our exercise of matching the key moments in the U.S. data. Figure 1 shows the patterns for a number of key moments and outcomes as we change the 
overhead labor parameter $f$, keeping all other parameters constant. ${ }^{22}$ The vertical line in Figure 1 shows the benchmark calibration for the U.S. As the overhead costs are reduced relative to the benchmark, the OP covariance term is reduced, the standard deviation of LPR is reduced and the firm survival rate increases. It is clear from Figure 1 that overhead labor plays a critical role in matching a number of key features of the U.S. data. First, it is critical for matching the finding that there is greater dispersion of revenue labor productivity relative to revenue total factor productivity. Second, overhead labor is critical for matching the magnitude of the OP covariance term. Starting from low overhead, the OP covariance term increases substantially until the U.S. benchmark. ${ }^{23}$ Third, overhead labour is critical for capturing the high pace of exit of recent entrants. It is also worth noting (see more below on this point) that the presence of overhead labor is a distinguishing feature of our theoretical model and analysis compared with that in the recent literature. ${ }^{24}$

Figure 1 also helps illustrate the difficulty of matching all of the U.S. moments exactly. The Figure shows that, as overhead labor rises, the covariance between size and productivity first rises sharply but then becomes flat and eventually declines with further increases in overhead labor. This non-monotonicity makes it difficult to match all the U.S. moments exactly. The underlying reason for the non-monotonicity is suggested by another key pattern in Figure 1 - that is, the share of entering firms that survive declines monotonically with overhead labor costs. Eventually overhead labor costs become sufficiently high that much of the distribution of firms is

22 Underlying figure 1 is variation in $f$. We present the results showing the implied variation in overhead costs (share of labor going to overhead) since this is a more easily interpretable metric.

23 Note that even with low overhead, there is still positive covariance for LPR given other frictions.

24 In particular, Hsieh and Klenow (2009) do not consider fixed operating costs and have no endogenous firm selection. Restuccia and Rogerson (2008) permit fixed operating costs in the specification of their model, but set these costs equal to zero in their calibration. As it is apparent in Figure 3, it would not be possible for us to match the patterns in the U.S. data without including fixed operating costs in the form of overhead labor in our model. 
cut off by selection and this yields a decline in the covariance. In like fashion, the standard deviation of LPR, while also initially rising sharply with higher overhead labor, eventually becomes flat with respect to further increases. This pattern also reflects the selection effects. These selection effects play an important role in the results below.

\section{The Impact of Misallocation Distortions}

We now turn to assess the potential role of misallocation distortions. Our objective is twofold. First, we seek to explore the implications of such misallocation distortions for key outcomes of the economy - both to understand the mechanisms through which misallocation distortions may be working but also to assess their impact on welfare-related variables such as consumption. Second, we explore whether the patterns of dispersion and covariance displayed in Tables 1 and 2 can be accounted for and understood in terms of differences in the distribution of misallocation distortions across countries.

We proceed as follows. First, we present results that show how misallocation distortions impact key moments and outcomes. This analysis is instructive to shed light on how misallocation distortions work in this class of models, in general, and in our specific version of the model calibrated as described above. Second, we explore the extent to which we can match the cross-country patterns of the key moments in Tables 1 and 2.

We begin with a relatively simple version of misallocation distortions, that is to say, permanent misallocation distortions that are uncorrelated with any fundamentals. Figure 2 shows the effect of increasing the dispersion of misallocation distortions on different moments. The distortions increase from left to right, starting from the non-distorted (U.S. benchmark) case. We find that an increase in the dispersion of distortions yields an increase in the standard deviation 
of TFPR, a modest effect on the standard deviation of LPR, a decrease in the OP covariance terms for LPR, TFPR, and TFPQ, a decrease in the fraction of surviving firms with an accompanying increase in the cost of entry as a share of output, an increase in the capital-labor ratio and a decline in consumption. Both the capital-labor ratio and consumption are indexed to the non-distorted economy, so an index above (below) one indicates the variable has increased (decreased) relative to the non-distorted economy. ${ }^{25}$

It is clear from Figure 2 that increasing the dispersion of the misallocation distortions has non-trivial effects on a number of indicators. One of them is the effect on the selection margin. As the "noise" from distortions is added, the churning of businesses that pay the sunk cost increases and this has significant effects, for example on consumption. In turns, the strong sensitivity of the selection margin implies that, while the dispersion in TFPR rises with the dispersion in distortions, as expected the quantitative increase is relatively small. In like fashion, the quantitative decline in the OP covariance terms is relatively small. The reason for these outcomes is that the selection effect truncates the lower-end of the distribution of firms, which mitigates the impact on the other key moments.

A much stronger effects of distortions on the economy can be obtained by allowing their distribution to be positively correlated with the idiosyncratic productivity draw. ${ }^{26}$ This positive correlation case could be interpreted as a form of progressive distortions, whereby firms that would otherwise be highly profitable and large given their high productivity are effectively taxed

25 For consumption, the log of aggregate consumption is computed and then converted to index form. For the capital-labor ratio, the log of the aggregate capital-labor ratio is computed and then converted into index form. The use of indices here are more interpretable given that level (even log level) units in the calibration are not meaningful. The remaining moments are all unit free.

Restuccia and Rogerson (2008) also consider correlated distortions and obtain broadly similar implications that correlated distortions have more of a quantitative effect. In their exercise, they calibrate the benchmark model (non-distorted) to the U.S. size distribution and then consider the impact of misallocation distortions. They do not seek to account for cross country differences in observed moments. 
or induced to stay small. This hypothesis is consistent with empirical evidence (see e.g. the World Bank Investment Climate Survey, Aterido et al. 2007) suggesting that when regulations are very strict and enforcement more pronounced among large businesses and/or corruption and rent seeking loom large, it may be better to "fly beneath the radar screen". Likewise, there is evidence, as best exemplified by the experience of the centrally-planned economies, which suggests that in countries characterised by widespread market- and policy-induced distortions, the largest businesses are not necessarily the most productive but rather those that receive preferential treatment.

Figure 3 shows the relationship between key moments and distortion dispersions when we allow the idiosyncratic productivity and the idiosyncratic distortion to be positively correlated. We set the positive correlation very high (about 0.95 ) and vary the dispersion of the distortions for this high degree of correlation. ${ }^{27}$ We observe similar qualitative patterns to those in Figure 2 but the quantitative variation is much greater for specific moments. In particular, we find that increasing the dispersion of distortions yields an increase in TFPR dispersion, an initial decline and then an increase in LPR dispersion, substantial reductions in the OP covariance terms for TFPQ, TFPR and LPR, a decline in survival with an accompanying increase in the entry cost as a share of aggregate output, a decline in the consumption index and an increase in the capital-labor ratio index.

What lessons can we draw from these calibrations? First, consistent with the intuition from Olley and Pakes (1996) and further interpretations in the literature, we find that economies characterised by sizeable scale distortions have distorted size-productivity relationships, as measured by the OP covariance terms for TFPQ, TFPR, and LPR. We think it is striking that the

$27 \quad$ For this case, we consider both permanent and transitory distortions. We have found that including both is important to match the patterns of the OP covariances across countries, which is not surprising given the presence of both permanent and transitory productivity shocks. 
impact of distortions on the covariances is similar across these alternatives. The ideal measure is the OP covariance using TFPQ and physical output since the canonical prediction of firm heterogeneity models is that, in the absence of distortions, this covariance should be positive. Moreover, it makes intuitive sense that scale distortions will reduce this covariance. Given the frictions we have included in our model, these patterns carry over to the covariance measures using TFPR and LPR.

Second, we find that, other than the size-productivity relationship, many other margins are affected, including the productivity dispersion, the selection margin and capital-labor ratio. Third, increases in the dispersion of distortions across firms reduce consumption. Fourth, the impact of the increase in the dispersion of distortions on the OP covariance terms and on productivity dispersion is much greater if the distortions are positively correlated with productivity. This makes intuitive sense as distortions in this case have greater bite as they are not just noise but actively induce the most productive firms to be smaller and the least productive firms to survive and be larger than would have been the case in a distortion-free environment.

We now turn to the second objective of our analysis where we try to match the observed cross-country differences in our key moments shown in Tables 1 and 2 by using differences in misallocation distortions alone. Figures 2 and 3 already suggest that it will not be feasible to match all of the patterns shown in Tables 1 and 2. It is clear from Figures 2 and 3 that matching the OP covariance term patterns is potentially feasible since there is strong monotonic relationship between increasing distortions and reducing the size-productivity relationship and Tables 1 and 2 show systematic patterns in the OP covariance terms across countries. However, Figures 2 and 3 also show that increasing distortion dispersion systematically yields some 
increase in the dispersion of TFPR but they do not show systematic patterns for the dispersion of LPR. Thus, matching these patterns with the distribution of distortions alone is not feasible.

Given this obvious challenge, we think it is instructive to show the patterns consistent with exactly matching the OP covariance terms in Table 1 . Table 3 shows the model and data moments in this case along with the implied model implications for consumption. As is apparent, the different distributions of distortions are chosen to match exactly the cross-country variation in the OP covariance terms for LPR. The implied cross-country variation in the standard deviation for LPR in the model at best only roughly matches the patterns in the data. That is, in our database, the Western European economies tend to have about the same LPR dispersion, and the model yields roughly similar patterns. However, the model does not come close to matching the very high standard deviation of LPR in the transition economies. The model is not effective in accounting for the cross-country patterns in the standard deviation of TFPR. ${ }^{28}$

Taken at face value, the model yields interesting implications for the consumption patterns across countries. The general pattern is that the implied consumption index for most Western European countries is about 0.95 of that in the U.S. while the transition economies have an implied consumption index of 0.90 or lower. An exception to this pattern is the U.K. which has an implied consumption index close to 0.90 associated with its very low measured OP covariance term for LPR.

The calibrated model is also capable of capturing the changes in covariance terms in Table 2 for the transition economies. Using Figure 3 and Table 3 together, an increase in the covariance term from around 0 to 0.20 is associated with an increase in the consumption index of economy by permitting a negative correlation between the idiosyncratic productivity and the distortion. However, even here we have not been able to match the full range of dispersion of TFPR in Table 1 . Moreover, the patterns for the OP covariance terms as we seek to match these patterns don't come close to matching those for Table 1. 
about 0.05 to 0.10 . So again taken at face value, our results suggest that the improved sizeproductivity relationship in the transition economies can be associated with a substantial increase in consumption as a result of an improved allocative efficiency.

Given that we are not able to match all of the patterns in Tables 1 and 2, how should we think about these results? First, the difficulty of matching the productivity dispersion patterns may reflect the fact that dispersion in productivity measures is less robust to measurement error than other moments. In that regard, we find our evidence in Table 2 instructive since it shows that for the transition economies the OP covariance terms increase substantially but there is little evidence of changes in the productivity dispersion. Given that changes over time cancel out any country-specific measurement error in second moments, we think that the changes are more robust measures in this context. But the lack of a systematic pattern in the changes in productivity dispersion is suggestive that other factors other than misallocation distortions are likely to be required to account for the cross-country time series patterns observed in the data.

What other factors might account for the observed patterns for the dispersion in TFPR? We leave formal exploration of this question for future work but note that it is well known in the empirical productivity dynamics literature that many factors impact the dispersion of productivity. For one, productivity dispersion is much greater for younger businesses (see, e.g., Haltiwanger, Jarmin and Schank (2003)). As such, the observed patterns may reflect differences in the dynamism of young businesses across countries. Drawing from our firm-level database that includes a measure of the dispersion of productivity of firms that entered the market within a five-year window, we find that in all countries, industries, and time periods considered in Tables 1 and 2, the dispersion of productivity of such young businesses is higher than the dispersion 
among incumbents. ${ }^{29}$ Second, market structure and competition impact the dispersion of productivity (see, e.g., Syverson (2004b)). Variation in competition across countries may reflect a form of misallocation distortions that affects the dispersion through a different channel than the distribution of idiosyncratic distortions as in our model.

Moreover, there are many additional margins that may be impacted by some form of misallocation distortion that are not well captured in this model. From the empirical firm dynamics literature, we have learned that the first decade or so of the life of a firm has very rich dynamics. In the U.S., we observe that for each entering cohort there is a rich "up or out" dynamic (see, e.g., Haltiwanger, Jarmin and Miranda (2009) and Davis, et al. (2008)) with most young businesses exiting but conditional on survival young businesses growing faster than their more mature counterparts. Moreover, the related evidence on productivity (see, e.g., Foster, Haltiwanger and Krizan $(2001,2006))$ is that the surviving young businesses have more rapid productivity growth than their more mature counterparts. One hypothesis is that what differs across countries is the nature of these post-entry dynamics (see., e.g., Bartelsman, Scarpetta and Schivardi (2005)). Another possibility is that the policy environment alters the decisions of firms to choose for risky versus safe innovative strategies (e.g. Bartelsman, Gautier, and de Wind, (2009)) thereby endogenously changing productivity dispersion. Exploring these margins is beyond the scope of this paper but highlights that the cross sectional moments that we emphasize in Tables 1 and 2 while interesting and instructive are unlikely to be the whole story.

At the end of the day, our view is that using this class of models to assess the potential effects of misallocation distortions is instructive for helping us to understand some of the dimensions of the productivity distributions observed within and between countries. In

29 For example, in the U.S., France, and Germany the dispersion of labor productivity is nearly 10 log points higher for younger businesses than more mature businesses in the same industry, while in Romania and Hungary the difference is about $25 \log$ points. 
particular, these models are well suited to exploring the size-productivity relationship within industries that we have found exhibit systematic patterns across countries and over time in the transition economies. However, the inability of these models to capture other features of the cross-country evidence makes clear that refinements and/or alternative approaches are also needed.

\section{Discussion of Results Relative to the Recent Literature}

How do our results compare to those obtained using similar models in the recent literature? We have already recalled some of their key features, but it is useful to briefly revisit them here. Restuccia and Rogerson (2008) provide the core theoretical development that much of the recent literature has subsequently used. They calibrate a non-distorted version of their model to the U.S. size distribution and then explore the impact of misallocation distortions on outcomes like aggregate output and productivity. Hsieh and Klenow (2009) calibrate their model to match the measured distributions of TFPR in the U.S., China and India. Since their model has the property that TFPR dispersion would be zero in the absence of distortions, their approach is to assess the role of relative differences in the distribution of misallocation distortions across the three countries analysed. Alfaro et. al. (2008) calibrate their model using differences in the relative size distribution of firms between the U.S. and other countries.

All of these recent papers share some common features with our analysis. In particular, they all consider heterogeneous production units - either in terms of the size distribution of activity or the dispersion in productivity and include idiosyncratic distortions that tend to have adverse impacts on key aggregate outcomes, such as output, consumption and productivity. 
Within this framework, our contribution relative to this recent literature is multi-fold. First, we are the first to consider the size-productivity relationship in this context. We regard this relationship as critical to the canonical models of the size distribution of activity that all of these recent papers build upon. That is, in the absence of distortions, these models have the property that the largest firms are the most productive ones. We think it is intuitive that misallocation distortions will have a non-trivial impact on the size-productivity relationship. We present novel empirical evidence on the size-productivity relationship using a sample of countries and explore the implications in the context of these models.

Second, we focus on the empirical finding from our analysis (consistent with results obtained in the recent empirical literature) that labor productivity dispersion is larger than total factor productivity dispersion. We regard this basic feature of the firm-level data important since it highlights possible frictions that need to be taken into account even in the absence of misallocation distortions.

Third, and in a closely related manner, we consider the role of misallocation distortions where there is a non-trivial role for endogenous selection. None of the recent papers we have just discussed calibrate their models using information on survival and exit. In our setting, the role of overhead labor plays a critical role in matching key patterns in the non-distorted benchmark and also, in turn, serves as a key factor in permitting endogenous selection. To help shed further light on the role of overhead labor and selection, we include some further robustness analysis in the next section. Lastly, because we focus on multiple moments from multiple countries, our paper highlights the impact of misallocation distortions on different margins. As such, we find that it is difficult to match the combined multiple moments with the evidence from multiple countries. In this respect, our analysis serves as a source of caution about this class of models. That is, it is 
apparent from our findings that only permitting the distribution of misallocation distortions across countries is not sufficient to match a number of key patterns in the data and the model.

\section{Robustness Analysis: What happens if there is low overhead labor?}

As discussed above, one distinguishing feature of our model and analysis is to allow for the effect of overhead labor on endogenous selection. It is thus of interest to assess the implications of our model simulations when we significantly diminish the role for overhead labor. For this purpose, we set the overhead labor sufficiently low so that all firms from the exante productivity distribution produce in the absence of distortions. We know from Figure 1 that this implies that we cannot come close to match the U.S. moments for labor productivity dispersion or selection. Accordingly, for this exercise we benchmark the non-distorted economy to match the standard deviation of TFPR for the U.S.

Figure 4 presents the simulated results when we increase the dispersion of distortions (starting from zero). As in Figure 3, we focus on the correlated case. Several interesting patterns emerge. First, given the very low overhead labor, there is a substantial range over which increasing distortions has no impact on selection. However, for sufficiently large distortion dispersion, selection begins to bite. We intentionally did not set overhead costs to zero since we wanted to show that, if enough dispersion is introduced, this will push some firms to operate at a such a small scale that they will not be able to cover their overhead labor costs, however small.

Second, it is clear from the upper-right panel of Figure 4 that productivity dispersion both in terms of TFPR and LPR rises much more rapidly with distortion dispersion when selection is not playing a role (for this purpose it is useful to compare Figures 3 and 4). It should be noted that, as selection becomes relevant, productivity dispersion in both TFPR and LPR rises less rapidly with distortion dispersion. The main message of this is that when overhead labor 
(fixed costs) and selection are at work, it becomes difficult to match a wide range of productivity dispersion using widening distortion dispersion.

Third, we find a general pattern of the covariance between size and productivity declining with distortion dispersion even with low overhead labor, although the patterns are somewhat more complex for LPR. For TFPQ, we find that the covariance between size and productivity falls monotonically with distortion dispersion. This pattern is also present in Figure 3 where overhead labor and selection is relevant over the entire range. A robust implication of these models is that the covariance between size and productivity when using TFPQ is declining in distortion dispersion. This is intuitive and, in part, underlies our basis approach in this paper. Indeed, as we stated in the introduction, a core implication of models of firm heterogeneity in the absence of distortions is that higher TFPQ firms will be larger. Moreover, it makes sense that distortions to allocation will affect this covariance. Ideally, our data sources would include firmlevel prices so that we could measure this covariance moment that is most robustly linked to distortions.

However, measuring TFPQ directly is typically not feasible and we find the patterns for TFPR and LPR in Figure 4 of interest as well. For TFPR, we tend to find a decreasing relationship between the covariance for TFPR and distortion dispersion but this really kicks in once distortion dispersion gets sufficiently large. For LPR, the covariance first increases over some range and then declines. The increasing portion reflects the fact that in the absence of distortions and overhead labor, there is relatively low LPR dispersion (see upper right panel). The magnitude of the covariance depends on the magnitude of dispersion so over some range dispersion in LPR is so low that the covariance with LPR is also low. 
We don't find it surprising that the patterns for LPR are less systematic in a low overhead labor environment with low distortion dispersion. As is apparent from Figure 4 (and from the earlier analysis), with low overhead labor we cannot match the observed pattern that LPR has greater dispersion than TFPR. Again, recall that this is a robust finding for all countries in Table 1 (and also a robust finding in Syverson (2004a)). With low overhead labor, this pattern can only be met with sufficiently large dispersion in idiosyncratic distortions. To match data from the U.S., where we assume there are no idiosyncratic distortions, we expanded the basic model with frictions such as overhead labor and quasi-fixed capital. In the literature, an alternative approach (e.g., Hsieh and Klenow (2009)) has been to match to U.S. patterns assuming that it has sufficient idiosyncratic distortions rather than frictions. Put differently, the sufficient distortions needed to match U.S. patterns might be thought of as a proxy for frictions not included in their model. Viewed from this perspective, we find that the patterns in Figure 4, over the distortion dispersion range where $\mathrm{STD}(\mathrm{LPR})>\mathrm{STD}(\mathrm{TFPR})$ match the patterns in Figure 3 , i.e. that increases in distortions yield increases in dispersion of productivity and declines in all of the alternative covariance measures.

\section{Concluding Remarks}

In this paper, we provide empirical evidence that the within-industry distributions of productivity and size are closely related to each other and that this relationship varies significantly across countries. Using the Olley and Pakes (1996) decomposition, we provide a summary measure of the extent to which size and productivity exhibit positive covariance within industries. The evidence presented suggests that the size/productivity relationship is stronger in the more advanced economies, although there are large differences even within this group of 
countries, and becomes stronger for transition economies as they progress in the transition to a market economy.

We confront these interesting patterns in the data with a model that seeks to account for variation in outcomes due to misallocation distortions. Our simple model with heterogeneous firms facing frictions (overhead labor quasi-fixed capital) and idiosyncratic productivity shocks and distortions provides a reasonable match to key patterns in the U.S. indicators of productivity and size built up from firm-level data. In particular, the model captures high dispersion in revenue based measures of total factor and labor productivity. Second, it captures the finding that dispersion in labor productivity dispersion is greater than dispersion in total factor productivity. Third, it captures the large positive covariance between size and productivity in the data. Finally, it captures the finding that, for any entering cohort, a large fraction of firms exit very quickly.

Using this model, we seek to match the cross-country variation in a number of these key moments using differences in the distribution of misallocation distortions alone. We are successful in matching one of the key patterns in the cross country evidence. That is, we find that the size-productivity relationship is much stronger in the U.S. than in Western Europe and, in turn, it is stronger in Western Europe than in the transition economies of Eastern Europe. Moreover, the transition economies exhibited large increases in the size-productivity covariance over the 1990s while the U.S. and Western Europe did not. In matching these patterns, our calibrated model implies relatively large difference in consumption due to these misallocation distortions.

While we are quite successful in matching the size-productivity covariance patterns, we are less successful matching other patterns in the data. In particular, the theoretical model implies 
that dispersion in revenue based measures of total factor productivity should monotonically increase with an increase in the dispersion of idiosyncratic misallocation distortions to businesses. While this pattern makes sense theoretically, there are not systematic patterns in the dispersion of revenue based measures of total factor productivity in the data. In the discussion of these results, we note that it may be that this moment is less robust to measurement error. However, it is equally likely that the model is not capturing the various different factors that influence the dispersion of productivity. Put differently, it may be asking too much to account for productivity dispersion patterns across countries in the context of these steady state models of misallocation distortions.

We think our analysis helps to shed further light on the potentials of this class of models of misallocation to track key productivity moments observed in the data. While we believe these models offer rich new insights they are quite simple relative to the theoretical and empirical models of firm behavior in the literature. For one, they are steady-state models with no meaningful dynamics. A large literature exists that models and empirically analyzes firm dynamics, including the role of selection and learning effects for young firms as well as the adjustment dynamics of capital and labor. A more refined or different approach will be needed to capture the potential distortions to these multiple margins. 


\section{References}

Alessandria, George, and Horag Choi. 2007. "Do Sunk Costs of Exporting Matter for Net Export Dynamics?" Quarterly Journal of Economics 122(1):289-336.

Alfaro, Laura, Andrew Charlton, and Fabio Kanczuk. 2008. "Plant-Size Distribution and Cross-Country Income Differences.” National Bureau of Economic Research Working Paper Series No. 14060.

Aterido Reyes, Mary Hallward-Driemeier and Carmen Pagés. 2007. "Investment Climate and Employment Growth: The Impact of Access to Finance, Corruption and Regulations Across Firms." IZA Discussion Papers 3138, Institute for the Study of Labor (IZA)

Baily, Martin Neil et al. 1992. "Productivity Dynamics in Manufacturing Plants." Brookings Papers on Economic Activity. Microeconomics 1992:187-267.

Banerjee, Abhijit V., and Esther Duflo. 2005. "Growth Theory through the Lens of Development Economics." In Handbook of Economic Growth, Elsevier, p. 473-552.

Bartelsman, Eric, John Haltiwanger, and Stefano Scarpetta. 2004. "Microeconomic evidence of creative destruction in industrial and developing countries." The World Bank, Policy Research Working Paper No. 3464, December.

Bartelsman, Eric, Stefano Scarpetta, and Fabiano Schivardi. 2005. "Comparative analysis of firm demographics and survival: evidence from micro-level sources in OECD countries." Industrial and Corporate Change 14, no. 3: 365-391.

Bartelsman, Eric, John Haltiwanger, and Stefano Scarpetta. 2009. "Measuring and Analyzing Cross-Country Differences in Firm Dynamics." In Producer Dynamics: New Evidence from Micro Data, T. Dunne, J.B. Jensen and M. Roberts (eds.). National Bureau of Economic Research, Inc. University of Chicago Press.

Bartelsman, Eric, Pieter Gautier, and Joris de Wind. 2009. "Employment Protection, Technology Choice, and Worker Allocation." mimeo.

Benassy, Jean-Pascal. 1996. "Taste for variety and optimum production patterns in monopolistic competition." Economics Letters 52(1):41-47.

Broda, Christian, and David E. Weinstein. 2006. "Globalization and the Gains from Variety." Quarterly Journal of Economics 121(2):541-585.

Davis, Steven J., R. Jason Faberman, John Haltiwanger, Ron Jarmin and Javier Miranda, 2008. "Business Volatility, Job Destruction, and Unemployment." NBER Working Papers 14300, National Bureau of Economic Research, Inc.

Foster, Lucia, John Haltiwanger, and C. J Krizan. 2006. "Market Selection, Reallocation, and Restructuring in the U.S. Retail Trade Sector in the 1990s." Review of Economics and Statistics 88(4):748-758.

Foster, Lucia, John Haltiwanger, and Chad Syverson. 2008. "Reallocation, Firm Turnover, and Efficiency: Selection on Productivity or Profitability?" American Economic Review 98, no. 1: 394-425. 
Foster, Lucia, John C. Haltiwanger, and C.J. Krizan. 2001. "Aggregate Productivity Growth: Lessons from Microeconomic Evidence.” In New Developments in Productivity Analysis, Chicago: University of Chicago Press.

Haltiwanger, J., S. Davis, R. Jarmin, and J. Miranda. 2007. "Volatility and Dispersion in Business Growth Rates: Publicly Traded and Privately Held Firms." NBER Macroeconomics Annual 2006.

Haltiwanger, John, Ron Jarmin, and Thorsten Schank. 2003. "Productivity, Investment in ICT and Market Experimentation: Micro Evidence from Germany and the U.S.", Center for Economic Studies, U.S. Census Bureau, February.

Haltiwanger, John, Ron Jarmin and Javier Miranda. 2009. "Who Creates Jobs? Small vs. Large vs. Young," mimeo

Hopenhayn, Hugo, and Richard Rogerson. 1993. "Job Turnover and Policy Evaluation: A General Equilibrium Analysis.” Journal of Political Economy 101(5):915-938.

Hopenhayn, Hugo A. 1992. "Entry, Exit, and Firm Dynamics in Long Run Equilibrium.” Econometrica 60(5), 1127-1150 .

Hsieh, Chang-Tai, and Peter J. Klenow. 2009. "Misallocation and Manufacturing TFP in China and India." Quarterly Journal of Economics (forthcoming).

Lucas, Robert E. 1978. “On the Size Distribution of Business Firms.” The Bell Journal of Economics 9(2):508523.

Melitz, Marc J. 2003. "The Impact of Trade on Intra-Industry Reallocations and Aggregate Industry Productivity." Econometrica 71(6):1695-1725.

Olley, G.Steven, and Ariel Pakes. 1996. "The Dynamics of Productivity in the Telecommunications Equipment Industry." Econometrica 64(6):1263-1297.

Pierre, Gaëlle, and Stefano Scarpetta. 2006. "Employment protection: Do firms' perceptions match with legislation?” Economics Letters 90(3):328-334.

Restuccia, Diego, and Richard Rogerson. 2008. "Policy distortions and aggregate productivity with heterogeneous establishments." Review of Economic Dynamics 11(4):707-720.

Scarpetta, Stefano. 2003. The sources of economic growth in OECD countries. OECD Publishing.

Syverson, Chad. 2004a. "Market Structure and Productivity: A Concrete Example.” Journal of Political Economy 112(6):1181-1222.

Syverson, Chad. 2004b. "Product Substitutability and Productivity Dispersion." Review of Economics and Statistics 86(2):534-550.

Venn, Danielle. 2009. "Legislation, Collective Bargaining and Enforcement: Updating the OECD Employment Protection Indicators," OECD, Social, Employment and Migration Working Papers, No. 89, July. 
World Bank. 2004. World Development Report 2005: A Better Investment Climate for Everyone. A World Bank Publication. 
Table 1: Within Industry Productivity Dispersion and OP Covariance Term

(weighted averages of industry-level data, U.S. Industry Weights)

\begin{tabular}{lc|c|c|}
\hline \hline & STD in Revenue Labor Productivity & STD in Revenue Total Factor Productivity & OP covariance term \\
United States & 0.58 & 0.38 & 0.51 \\
United Kingdom & 0.57 & 0.41 & 0.16 \\
Germany & 0.72 & NA & 0.28 \\
France & 0.53 & 0.22 & 0.24 \\
Netherlands & 0.56 & 0.15 & 0.30 \\
Hungary & 1.03 & 0.91 & 0.18 \\
Romania & 1.05 & 0.56 & -0.03 \\
Slovenia & 0.80 & 0.22 & 0.05 \\
\hline \hline
\end{tabular}

Notes: Averages over 1992-2001 data. Industry-level firm based TFP measures not available for Germany. 
Table 2: Changes in Productivity Dispersion and OP Covariance Term

(weighted averages of industry-level data, U.S. Industry Weights)

\begin{tabular}{lc|c|c|}
\hline \hline & STD in Revenue Labor Productivity & STD in Revenue Total Factor Productivity & OP covariance term \\
United States & 0.02 & 0.00 & 0.09 \\
\cline { 2 - 4 } United Kingdom & 0.04 & 0.03 & 0.06 \\
Germany & 0.06 & NA & 0.15 \\
France & NA & NA A \\
Netherlands & 0.01 & 0.00 & 0.11 \\
Hungary & -0.03 & -0.03 & 0.21 \\
Romania & 0.03 & -0.03 & 0.25 \\
Slovenia & -0.06 & -0.02 & 0.16 \\
\hline \hline
\end{tabular}

Note: Change is difference in moment between average value in 1996-2001 and the average value in 1992-1995. Data for France only available from 1992-1995. 
Table 3. Key data moments and model moments when the model is calibrated to match the OP LPR covariance

\begin{tabular}{|c|c|c|c|c|c|c|c|}
\hline & \multicolumn{2}{|c|}{ COV LPR } & \multicolumn{2}{|c|}{ STD LPR } & \multicolumn{2}{|c|}{ STD TFP } & \multirow{2}{*}{$\begin{array}{c}\text { Consumption } \\
\text { index } \\
\text { Model }\end{array}$} \\
\hline & Data & Model & Data & Model & Data & Model & \\
\hline United States & 0.51 & 0.51 & 0.58 & 0.68 & 0.38 & 0.43 & 1.00 \\
\hline United Kingdom & 0.16 & 0.16 & 0.57 & 0.58 & 0.41 & 0.61 & 0.91 \\
\hline Germany & 0.28 & 0.28 & 0.72 & 0.55 & na & 0.57 & 0.95 \\
\hline France & 0.24 & 0.24 & 0.53 & 0.54 & 0.22 & 0.58 & 0.94 \\
\hline Netherlands & 0.30 & 0.30 & 0.56 & 0.55 & 0.15 & 0.56 & 0.95 \\
\hline Hungary & 0.18 & 0.18 & 1.03 & 0.57 & 0.91 & 0.60 & 0.91 \\
\hline Romania & -0.03 & -0.03 & 1.05 & 0.63 & 0.56 & 0.62 & 0.87 \\
\hline Slovenia & 0.05 & 0.05 & 0.80 & 0.61 & 0.22 & 0.62 & 0.87 \\
\hline
\end{tabular}


Figure 1. The impact of overhead costs on key moments

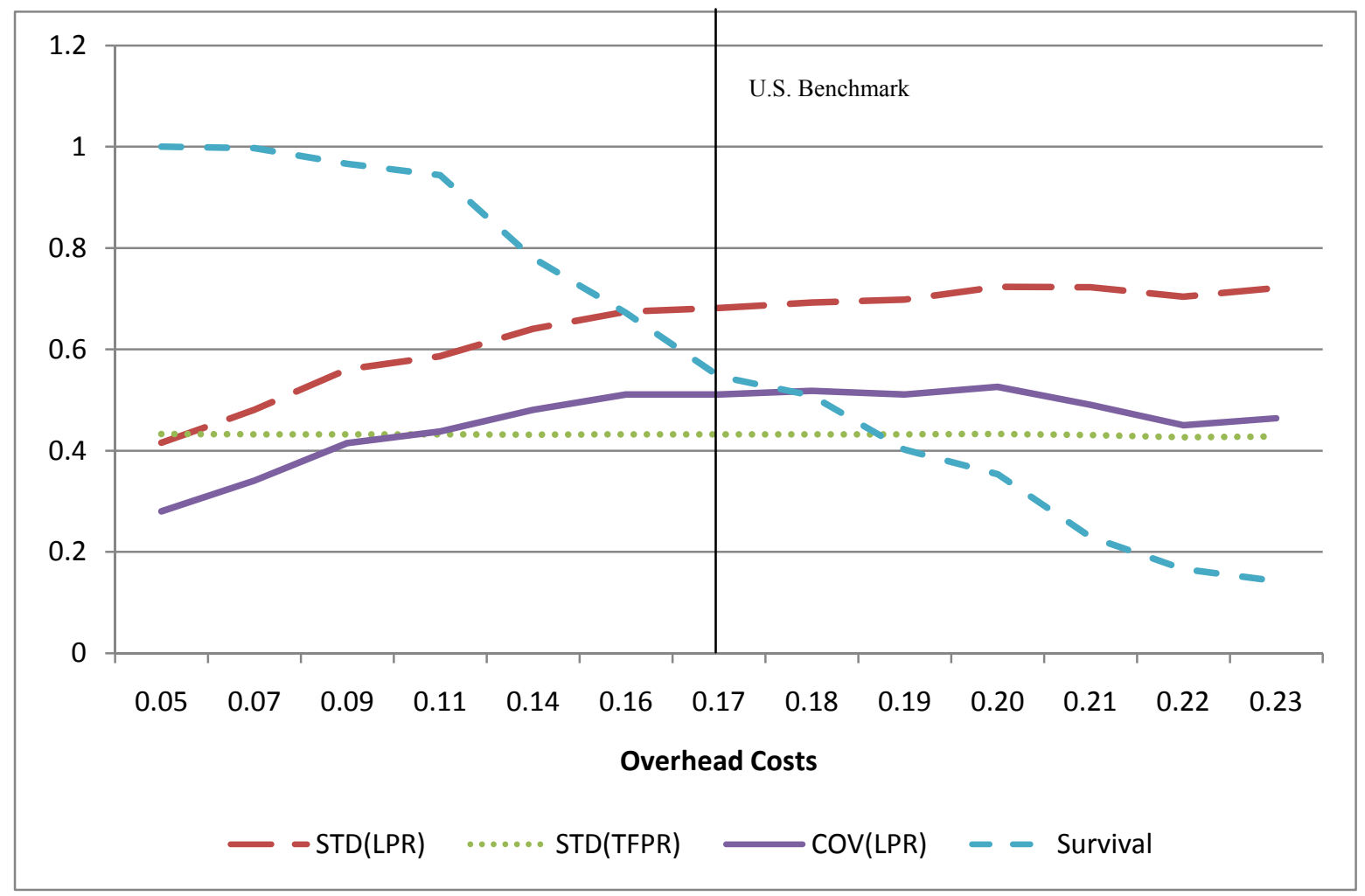


Figure 2: The Relationship Between Key Moments and Outcomes with Distortion Dispersion (Uncorrelated Case)
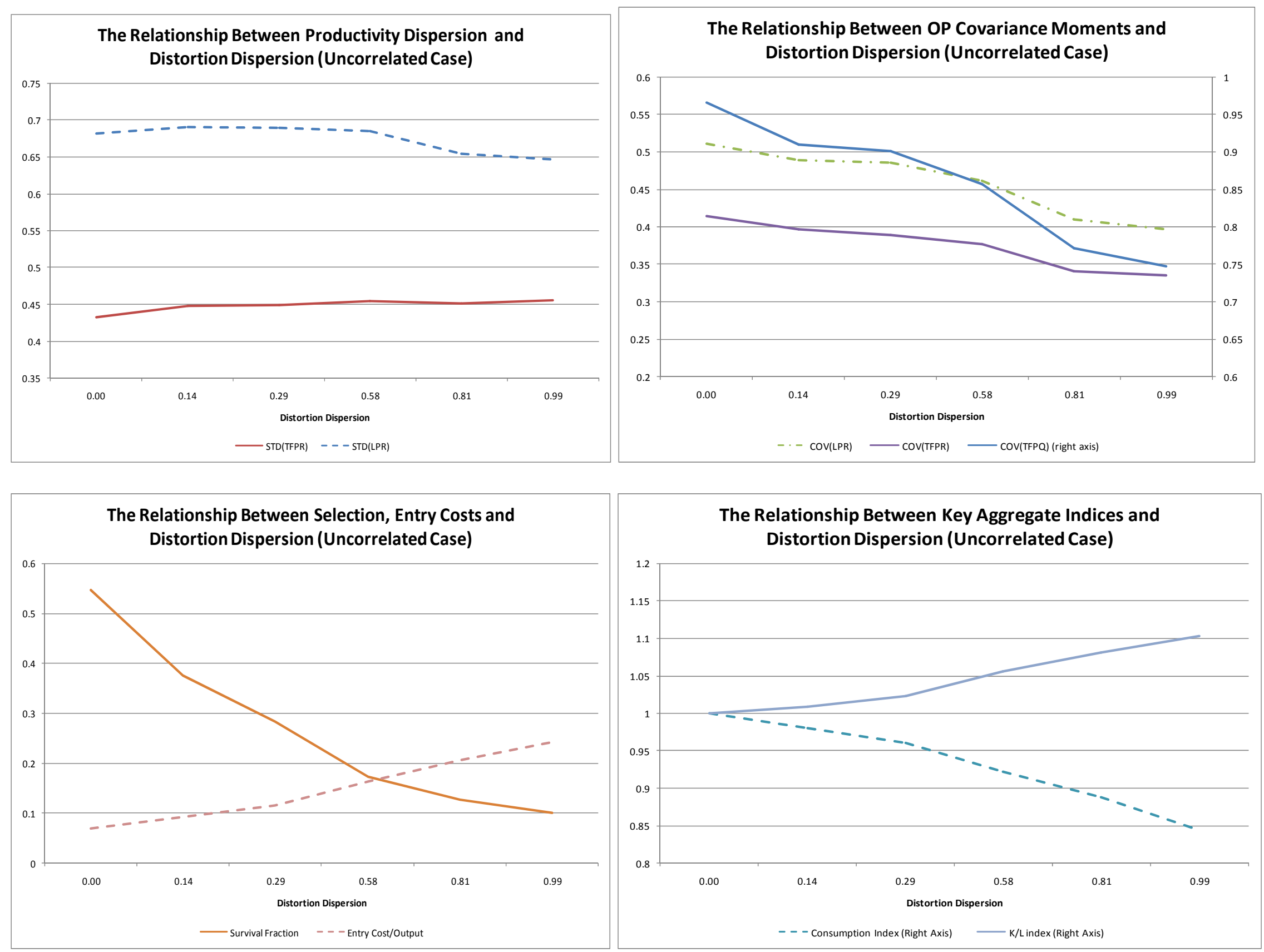
Figure 3: The Relationship Between Key Moments and Outcomes with Distortion Dispersion (Positive Correlation Case)
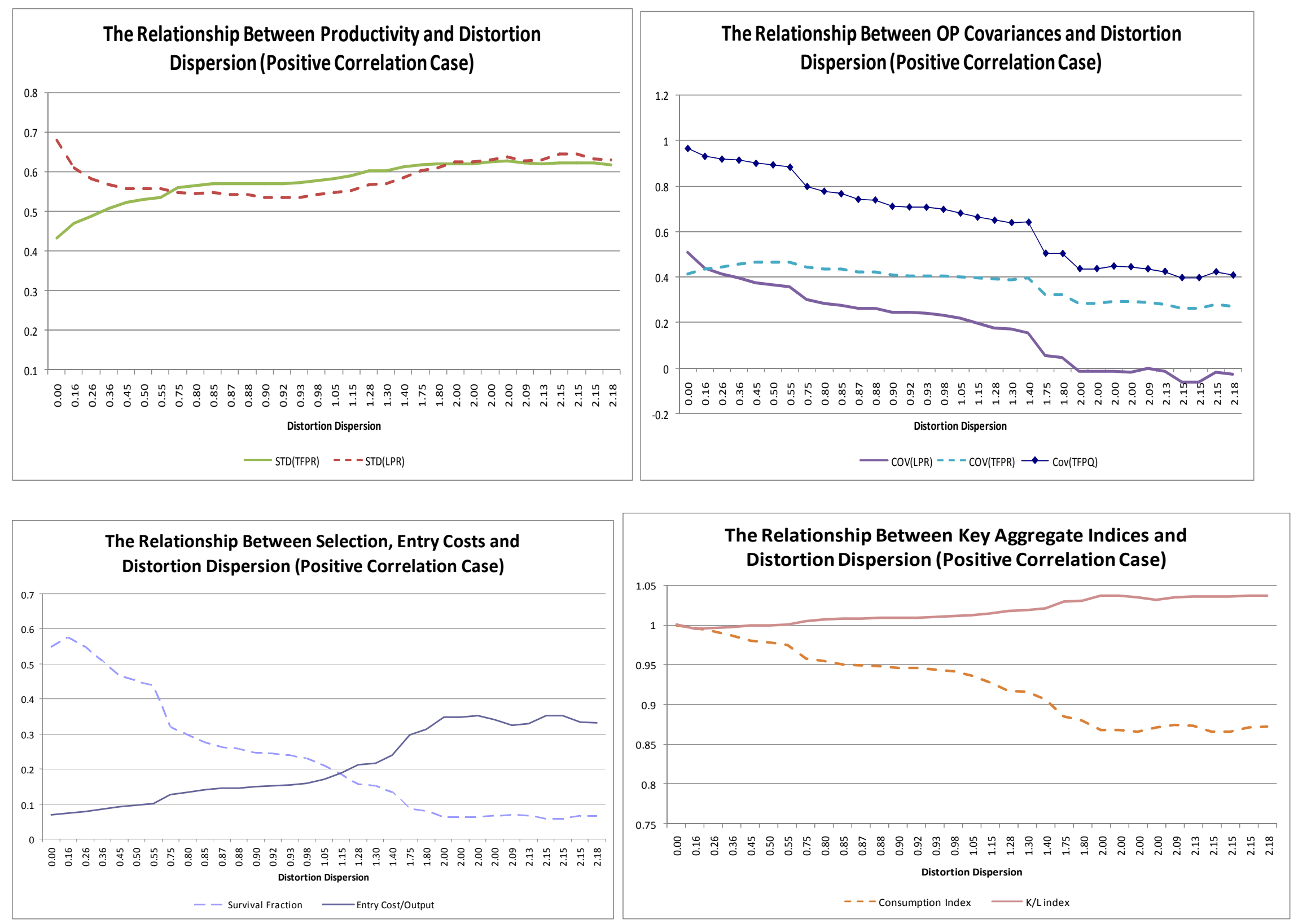
Figure 4: The Relationship Between Key Moments and Outcomes with Distortion Dispersion (Positive Correlation Case) and Low Overhead Labor
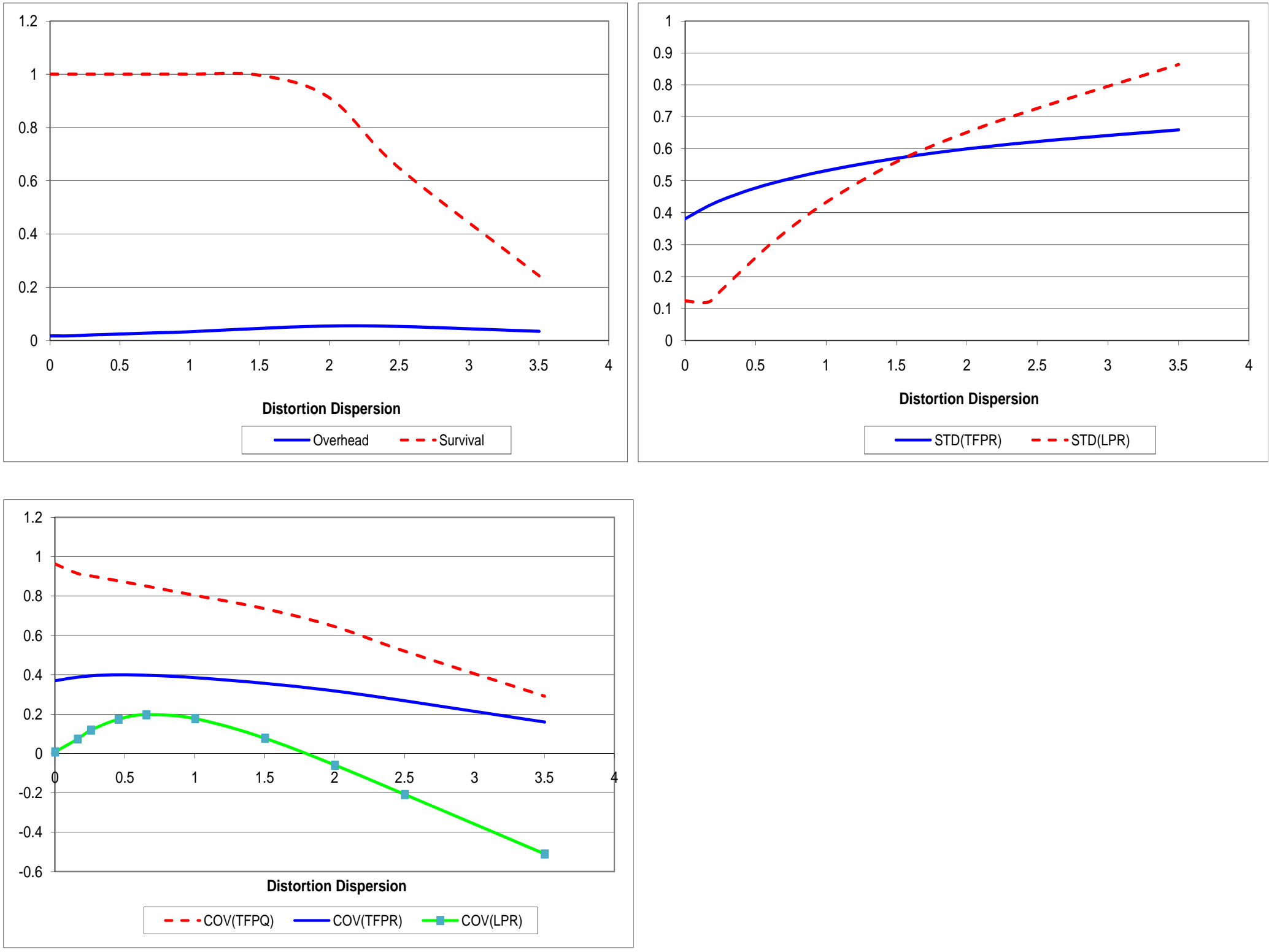